\title{
Associations between HLA and antibodies to collagen in rheumatoid arthritis
}

\author{
M J Rowley, B Tait, T Doran, P Emery, I R Mackay
}

\begin{abstract}
Associations between HLA types and serum antibodies to native and denatured type II collagen were sought in 105 patients with rheumatoid arthritis (RA). Antibodies were measured using a solid phase radioimmunoassay. There were no significant associations between any HLA antigens (A, B, or DR) and a high antibody titre to native collagen. There were significant associations, however, between HLA antigens and high antibody titres to denatured collagen. Although DR4 did not show an association, the phenotype $\mathrm{A2}^{+} \mathrm{DR4}^{+}$did; this was not related to $\mathrm{A2}$ as $\mathrm{A2}^{+} \mathrm{DR}^{-}$was not associated with a high antibody titre. No single $B$ locus antigen showed an association, but several $B$ locus antigens, $B 12, B 15$, and B40, were included in phenotypes with $A 2$ and DR4 which were associated with a high antibody titre to denatured collagen. These HLA associations with anticollagen type II are best explained by a gene other than DR4 (but in linkage with it) which may regulate the antibody response to denatured collagen. If so, this would represent an HLA gene in addition to DR4 that is active in RA.
\end{abstract}

Rheumatoid arthritis (RA) is a disease with strong immunogenetic associations. Although the primary HLA association found in RA has been with DR4, ${ }^{1}$ the distribution of other class I and class II HLA alleles is changed, and certain extended haplotypes ('supratypes') of DR4 occur more commonly than in a healthy population. ${ }^{23}$ Moreover, clinical studies have shown associations between HLA alleles and particular patterns of disease. ${ }^{4-6}$ In the study by Jaraquemada et al the prevalence of A2, Cw3, Bw62, Dw4, and DR4 was greater in patients with extraarticular disease, including digital or cutaneous vasculitis, fibrosing alveolitis, and neuropathy, and the prevalence of DR4, Dw4, and A2 was higher in patients with subcutaneous nodules. ${ }^{4}$ Sweatman et al have also shown an increased prevalence of $A 2$ and A28 in patients with obliterative bronchiolitis, with or without RA. ${ }^{7}$

Since the early claim that a response to type II collagen might contribute to the pathogenesis of $R A,{ }^{8}$ an experimental arthritis has been induced by immunising rodents with type II collagen. ${ }^{10}$ In mice susceptibility to arthritis induced by collagen is restricted to those strains with major histocompatibility complex (MHC) haplotypes bearing $\mathrm{H}-2 \mathrm{q}$, and such strains as those which produce high antibody titres to type II collagen after immunisation. ${ }^{11}{ }^{12}$ In man autoantibodies to collagen occur commonly in both the serum and synovial fluid of patients with RA. ${ }^{13-16}$ The disease specificity of this association has been contested, ${ }^{17}$ but with our use of a rigorous upper limit of normal we have not been able to support the claims that there are associations with other articular or inflammatory diseases including leprosy, or with other autoimmune connective tissue diseases in the absence of arthritis. We have noted, however, that some $15 \%$ of patients with systemic lupus erythematosus (SLE) who have polyarthritis also have antibodies to collagen (unpublished data). Accordingly, we see the association between RA and collagen antibodies as disease specific, although the importance of these antibodies has not yet been clarified.

We previously studied $40 \mathrm{HLA}$ typed patients with severe RA, many of whom had vasculitis, and showed that antibody titres to denatured collagen were significantly higher in the serum of those who were DR4 positive than in those who were DR4 negative; antibody titres were also non-significantly associated with those HLA haplotypes which are more prevalent in RA. ${ }^{13}$

This study was designed to achieve the following: $(a)$ extend our previous work on the association between antibodies to collagen and HLA types; $(b)$ include patients with less severe disease; $(c)$ examine associations between collagen antibodies and particular combinations of HLA types which are likely to be components of extended haplotypes (supratypes), and which have been associated with clinical subsets of disease.

\section{Patients and methods}

One hundred and five patients with confirmed $\mathrm{RA}$, diagnosed according to the criteria of the American Rheumatism Association ${ }^{18}$ and for whom HLA types and serum samples were available, were included in this study: Sixty seven (64\%) were DR4 positive and $38(36 \%)$ were DR4 negative; 37 had been tested for antibodies to collagen in the previous study ${ }^{13}$ using bovine collagen, but were retested using human collagen. For comparison, titres of antibody to collagen were measured in 50 healthy subjects.

\section{ANTIBODIES TO COLLAGEN}

Antibodies to native and denatured type II human collagen were measured in sera using the solid phase radioimmunoassay described previously. ${ }^{19}$ Microtitre plates were coated with native collagen or with collagen denatured at 
$50^{\circ} \mathrm{C}$, at a concentration of $30 \mu \mathrm{g} / \mathrm{ml}$ collagen Protein A labelled with ${ }^{125}$ I was used to detect IgG antibodies bound to the collagen. Serum samples were tested in duplicate, at a dilution of 1/100. Each serum sample was tested in the presence and absence of collagen, and the background binding in the absence of antigen was subtracted from the total counts bound for each serum tested. Serum samples from patients with RA and the comparison groups were tested together.

\section{HILA TYPING}

Typing for HLA-A, B, and DR was done by standard microlymphocytotoxicity procedures. $^{20}{ }^{21}$ DRw53 was estimated by its association with DR4, DR7, and DR9.

\section{HLA ASSOCIATIONS}

Three groups of HLA associations were assessed:

(i) Phenotypes which are more prevalent in $R A$, and which, from the findings of our previous study, ${ }^{13}$ may be associated with high antibody titres. These included DR4 and the haplotypes A2; B12; DR4; A2; B15; DR4 and A2; B40; DR4 ${ }^{2}$ and also DRw53 (MT3). ${ }^{22-24}$

(ii) Phenotypes which occur less often in RA. These include DR2 and A3; B7; DR2, ${ }^{4} 62526$ which were previously shown to be associated with a non-significant decrease in antibody to denatured collagen. ${ }^{13}$

(iii) DR3 and the haplotypes A1; B8; DR3 which have been associated with certain autoimmune diseases ${ }^{27-29}$ and with high antibody titres to native collagen ${ }^{30} 31$ but not denatured collagen. ${ }^{13}$

Antibody was measured as counts per minute (cpm) of radioactivity bound in the radioimmunoassay at a $1 / 100$ dilution to serum. For convenience the cpm for each assay was taken to specify the titre of anticollagen antibody, and results were expressed as mean cpm (SD). As antibody titres within the group with $\mathrm{RA}$ were not normally distributed, however, statistical analysis was carried out by the two tailed nonparametric Mann-Whitney U test. Differences were regarded as non-significant if the probability that they arose by chance was greater than 0.05 . As there was an a priori reason for the analyses, no correction was applied for multiple comparisons.

\section{Results}

The mean antibody titre (1 SD) to native collagen in the 50 healthy controls was 426 (258) $\mathrm{cpm}$ and the mean antibody titre in the patients with RA was $1110(1820)(\mathrm{p}<0.001)$. No significant associations between any HLA haplotypes and a high antibody titre to native collagen were evident (data not shown).

The mean antibody titre to denatured collagen for the 50 healthy controls was 1860 (874) cpm and that for the patients with RA was $\mathbf{4 2 0 0}$ (4520) cpm $(\mathrm{p}<0.001)$
COLLAGEN ANTIBODIES IN DR4 AND DR4 ASSOCIATED HAPLOTYPES

Associations between HLA and antibody titres to denatured collagen are shown in the table and figure. The mean titre of $4520(4960) \mathrm{cpm}$ in the 67 patients who were DR4 positive was not significantly higher than the mean of 3630 (3600) cpm in the 38 patients who were DR4 negative. To look at possible haplotypes associated with DR4, combinations of $A, B$, and DR alleles were examined and patients who were presumed to possess the three most common haplotypes, A2;B12;DR4, A2;B15;DR4, and A2;B40;DR4 were compared with those who did not possess all three. The mean antibody titre of 5820 (5420) was higher in the 23 patients with these putative haplotypes than the mean of

Mean (SD) antibody titres to denatured type II collagen in patients with and without phenotypes shown

\begin{tabular}{|c|c|c|c|}
\hline Phenotype & Positive & Negative & p Value \\
\hline DR4 & $\begin{array}{l}4520(4960) \\
(n=67)\end{array}$ & $\begin{array}{l}3630(3600) \\
(n=38)\end{array}$ & \\
\hline $\left.\begin{array}{l}\text { A2;B12;DR4 } \\
\text { A2;B15;DR4 } \\
\text { A2;B40;DR4 }\end{array}\right\}$ & $\begin{array}{l}5820(5420) \\
(n=23)\end{array}$ & $\begin{array}{l}3750(4160) \\
(n=82)\end{array}$ & $\begin{array}{l}0.053 \\
\text { NS }\end{array}$ \\
\hline $\mathrm{A} 2+\mathrm{DR} 4$ & $\begin{array}{l}5530(5610) \\
(n=43)\end{array}$ & $\begin{array}{l}3280(3330) \\
(n=62)\end{array}$ & 0.026 \\
\hline $\begin{array}{l}\text { DR4 positive only: } \\
\text { A2 }\end{array}$ & $\begin{array}{l}5530(5610) \\
(n=43)\end{array}$ & $\begin{array}{l}2730(2800) \\
(n=24)\end{array}$ & 0.013 \\
\hline $\begin{array}{l}\text { DR4 negative only: } \\
\text { A2 }\end{array}$ & $\begin{array}{l}3800(4060) \\
(n=28)\end{array}$ & $\begin{array}{l}3170(1900) \\
(n=10)\end{array}$ & \\
\hline DRw53 & $\begin{array}{l}4480(4740) \\
(n=76)\end{array}$ & $\begin{array}{l}3520(4030) \\
(n=27)\end{array}$ & \\
\hline DR2 & $\begin{array}{l}3730(3970) \\
(n=22)\end{array}$ & $\begin{array}{l}4330(4670) \\
(n=83)\end{array}$ & \\
\hline A3;B7;DR2 & $\begin{array}{l}2380(1650) \\
(n=8)\end{array}$ & $\begin{array}{l}4350(4650) \\
(n=97)\end{array}$ & \\
\hline DR3 & $\begin{array}{l}4900(5800) \\
(n=29)\end{array}$ & $\begin{array}{l}3980(3930) \\
(n=76)\end{array}$ & \\
\hline A1;B8;DR3 & $\begin{array}{l}3480(3480) \\
(n=19)\end{array}$ & $\begin{array}{l}4360(4730) \\
(n=86)\end{array}$ & \\
\hline
\end{tabular}

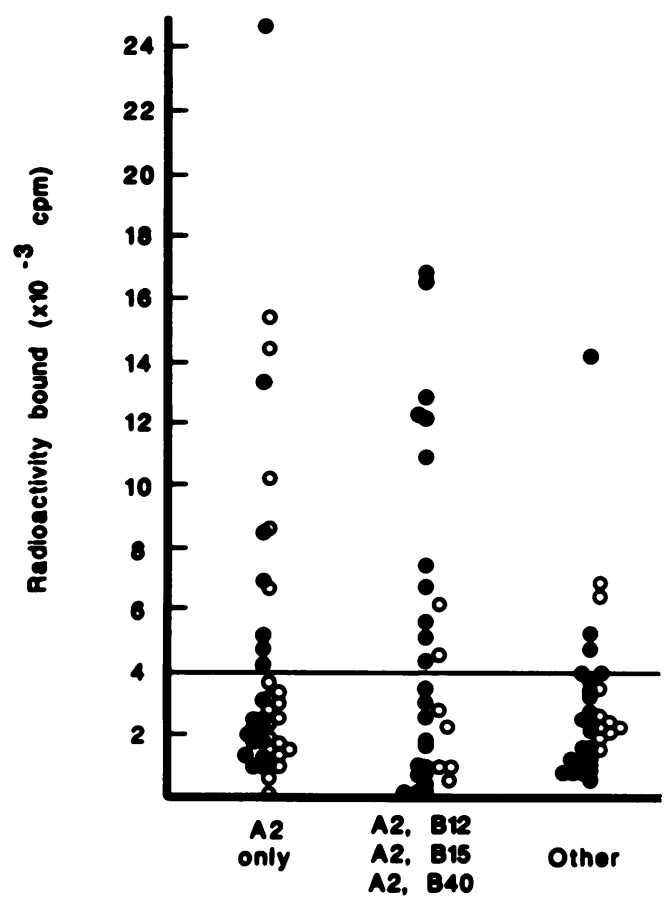

Antibody titres to denatured collagen, measured as counts of radioactivity bound in the radioimmunoassay, in patients with rheumatoid arthritis, grouped according to HLA phenotype. Horizontal line represents upper limit of normal (mean $+3 S D$ of the control group). $=D R 4$ positive; $\mathrm{O}=D R 4$ negative. 
$3750(4160)$ in the remaining 82 patients, but the difference was non-significant $(p=0.053)$. When A2 and DR4 were considered together, however, the mean of 5530 (5610) in the 43 patients who were A2 and DR4 positive was significantly higher $(p=0.026)$ than the mean of 3280 (3330) in the 62 patients who lacked A2 and DR4. Moreover, the mean antibody titre in the 23 patients with the putative haplotypes did not differ from the mean of 5190 (5950) in the 20 patients who were $A 2$ and DR4 positive but who were not positive for B12, B15, or B40; no single haplotype would explain the high titres of antibodies in these 20 patients, although B7 or B8, which may occur in haplotypes of DR4, were present in several patients.

To determine whether A2 alone was implicated an association between $\mathrm{A} 2$ and a high titre of antibodies was sought separately in patients who were DR4 positive and DR4 negative. For those who were DR4 positive the mean antibody titre of $5530(5610)$ in the 43 patients who were A2 positive was significantly higher $(p=0.013)$ than that of $2730(2800)$ in the 24 who were A2 negative. For those who were DR4 negative, the mean antibody titre of 3800 (4060) was not significantly higher in the 28 patients who were $A 2$ positive than that of 3170 (1900) in the 10 who were A2 negative. Thus high antibody titres were related to the combination of $A 2$ and DR4 rather than to either alone.

No other significant associations were obtained, although mean titres of antibodies to denatured collagen tended to reflect the known effects of HLA on susceptibility to RA. Thus those patients who were DRw53 positive had higher titres of antibody and those patients who were DR2 or A3; B7; DR2 positive had lower titres.

\section{Discussion}

The association between RA and HLA-DR4 is well established and may reflect the presence of a disease susceptibility gene associated with, or closely linked to, DR4. ${ }^{2}$ Goronzy et al have used $T$ cell clones to identify $\mathrm{Dw} 14$ associated $\mathrm{T}$ cell epitopes in all patients with RA tested, ${ }^{32}$ whether DR4 positive or negative, and suggest that there may be a specific polymorphism(s) within MHC class II molecules that can lead to recognition of an unknown antigen by $T$ lymphocytes. Several genetic studies in RA have suggested that more than one gene is involved in pathogenesis, ${ }^{33-35}$ and clinical subsets of the disease may be associated with different combinations of HLA antigens. ${ }^{4536}$

One antigen which may be inappropriately recognised in RA might be type II collagen. Both cellular and humoral immunity to collagen have been shown in RA, but HLA associations with the response to collagen have not been clearly shown. Increased cellular ${ }^{37}$ and humoral $^{13} 39$ responses to collagen have been linked to DR4, but other studies, albeit smaller, have failed to confirm these results. ${ }^{3040-42}$ Antibodies to native type II collagen, which are increased in the serum in only about $10 \%$ of patients with RA, have been linked with HLA-
DR3 and DR7, ${ }^{30}{ }^{31}$ but this was not observed in our study.

We have reported the effect of selected HLA types, which have hitherto been linked either positively or negatively with susceptibility to RA, on titres of antibodies to human denatured type II collagen. The specificities examined included DR4, A2+DR4, and the putative haplotypes of DR4, A2;B12;DR4, A2;B15;DR4, and A2;B40;DR4, DRw53, DR2, and A3;B7;DR2, and DR3 and $A 1 ; B 8 ; D R 3$. In each case mean antibody titres to denatured collagen in patients with varying HLA haplotypes tended to reflect the known effects of HLA on susceptibility to RA. Thus those patients who were DR4 and DRw53 positive had higher titres, and those patients who were DR2 or A3;B7;DR2 positive had lower titres, though no single class I or class II allele was itself significantly associated with high titres of antibodies. Interestingly, A2 and DR4 together were the best markers for high antibody titres to denatured collagen, perhaps reflecting the effect of an unknown gene which occurs in extended haplotypes of DR4; in this study we were unable to identify such haplotypes by their A, B, and DR antigens. Perhaps these HLA associations with anticollagen type II are best explained by a gene other than DR4, but in linkage with it, which may regulate the antibody response to denatured collagen. If so, this would represent an HLA gene other than DR4 that is activated in rheumatoid arthritis.

We thank the members of the department of rheumatology of the Royal Melbourne Hospital for their cooperation and access to patients. Dr Rowley was supported by a National Research Fellowship. Drs Mackay and Emery were supported by a gran from the National Health and Medical Research Council of Australia.

1 Stastny P. Associations of the B-cell alloantigen DRw4 with rheumatoid arthritis. N Engl f Med 1978; 298: 869-71.

Dawkins R L, Christiansen F T, Kay P H, et al. Disease associations with complotypes, supratypes and haplotypes. Immunol Rev 1983; 70: 5-22.

3 Puttick A, Briggs D, Welsh K, Jacoby R, Williamson E Jones V. Extended haplotypes in rheumatoid arthritis and preliminary evidence for an interaction with immunoglobulin genes. Dis Markers 1986; 4: 139-44

4 Jaraquemada D, Ollier W, Awad J, et al. HLA and rheumatoid arthritis: a combined analysis of $\mathbf{4 4 0}$ Britis patients. Ann Rheum Dis 1986; 45: 627-36.

5 Ollier W, Venables P J W, Mumford P A, et al. HLA antigen associations with extra-articular rheumatoid arthritis. Tissue Antigens 1984; 24: 279-91

6 Young A, Jaraquemada D, Awad J, et al. Association of HLA-DR4/Dw4 and DR2/Dw2 with radiologic changes in a prospective study of patients with rheumatoid arthritis. a prospective study of patients with rheumatoid arthritis. Preferential relationship with HLA-Dw rather than

7 Sweatman M C, Markwick J R, Charles P J, et al. Histocompatibility antigens in adult obliterative bronchiolitis with or without rheumatoid arthritis. Dis Markers 1986; 4 $19-26$.

8 Steffen C, Timpl R. Antigenicity of collagen and its application in the serologic investigation of rheumatoid arthritis sera. Int Arch Allergy Appl Immunol 1963; 22: 333-49.

9 Trentham D E, Townes A S, Kang A H. Autoimmunity to type II collagen: an experimental model of arthritis. $\mathcal{J}$ Exp Med 1977; 146: 857-68.

10 Courtenay J S, Dallman M J, Dayan A D, Martin A, Mosedale B. Immunization against heterologous type II collagen induces arthritis in mice. Nature 1980;283: 666-8

1 Wooley P H, Luthra H S, Stuart J M, David C S. Type II collagen-induced arthritis in mice. I. Major histocompatibility complex (I region) linkage and antibody correlates. F Exp Med 1981; 154: 688-700.

12 Holmdahl R, Klareskog L, Andersson M, Hansen C. High antibody response to autologous type II collagen is restricted antibody response to autologous type II co

13 Rowley M, Tait B, Mackay I R, Cunningham T, Phillips B. Collagen antibodies in rheumatoid arthritis. Significance of antibodies to denatured collagen and their associat

14 Rowley M J, Williamson D J, Mackay I R. Evidence for local synthesis of antibodies to denatured collagen in the 
synovium in rheumatoid arthritis. Arthritis Rheum 1987; 30 $1420-5$

15 Stuart J M, Huffstutter E H, Townes A S, Kang A H. Incidence and specificity of antibodies to types I, II, III, IV and V collagen in rheumatoid arthritis and othe rheumatic diseases as measured by ${ }^{125}$ I-radioimmunoassay. Arthritis Rheum 1983; 26: 832-40.

16 Clague R B, Shaw M J, Holt P J L. Incidence of serum antibodies to native type I and type II collagens in patients with inflammatory arthritis. Ann Rheum Dis 1980; 39: 201-6.

17 Choi E K K, Gatenby P A, McGill N W, Bateman J F, Cole W G, York J R. Autoantibodies to type II collagen: occurrence in rheumatoid arthritis, other arthritides, autoimmune connective tissue diseases, and chronic inflamimmune connective tissue diseases, and chronic inflam
matory syndromes. Ann Rheum Dis 1988; 47: 313-22.

18 Ropes M W, Bennett G A, Cobb S, Jacox R, Jessar R A. 1958 revision of diagnostic criteria for rheumatoid arthritis. Bull Rheum Dis 1958; 9: 175-6.

19 Rowley M J, Gershwin M E, Mackay I R. Collagen antibodies in juvenile arthritis and adult rheumatoid arthritis: differences in levels and type-specificity. $\mathcal{F}$ Rheumatol 1988; 15: 289-93.

20 Terasaki P I, McClelland J D. Microdroplet assay of human serum cytotoxins. Nature 1964; 204: 998-1000.

21 Bodmer J G, Pickbourne P, Richards S. Ia serology. In: Bodmer W F, Batchelor J R, Bodmer J G, Festenstein H, Morris P J, eds. Histocompatibility testing 1977. CopenMorris P J, eds. Histocompatibility

22 Ohta N, Nishimura Y K, Tanimoto K, et al. Association between HLA and Japanese patients with rheumatoid arthritis. Hum Immunol 1982; 5: 123-32.

23 Young A, Jaraquemada D, Awad J, et al. Association of HLA-DR4/Dw4 and DR2/Dw2 with radiological changes in a prospective study of patients with rheumatoid arthritis. Arthritis Rheum 1984; 27: 20-5.

24 Sasazuki T. Immunogenetic analysis of rheumatoid arthritis. F Rheumatol 1983; 10 (suppl 10): 54-7.

25 Panayi G S, Wooley P H, Batchelor J R. Genetic basis of rheumatoid disease: HLA antigens, disease manifestations and toxic reactions to drugs. $\mathrm{Br}$ Med $\mathcal{F}$ 1978; ii: 1326-8.

26 Roberts D F, Wentzel J. Immunogenetics and rheumatology. In: Dick W C, ed. Immunological aspects of rheumatology. In: Dick W C, ed. Immunological aspects

27 Mackay I R, Tait B D. HLA associations with autoimmunetype chronic active hepatitis: identification of B8-DRw3 haplotype by family studies. Gastroenterology 1980; 79: 95-8.

28 Stastny P. Genetic control of the immune response and susceptibility for rheumatoid arthritis, lupus erythematosus and related diseases. In: Franklin E C, ed. Clinical immunology update. New York: Churchill Livingstone, 1981: 31-57.
29 Whittingham S, Mackay I R, Tait B D. Autoantibodies to small nuclear riboproteins: a strong association between
anti-SS-B(La), HLA-B8 and Sjögren's syndrome. Aust NZ anti-SS-B(La), H Med 1983; 13: 565-70.

30 Dyer P A, Clague R B, Klouda P T, Firth S, Harris R, Holt $P$ J L. HLA antigens in patients with rheumatoid arthritis and antibodies to native type II collagen. Tissue Antigens 1982; 20: 394-6.

31 Klimiuk P S, Clague R B, Grennan D M, Dyer P A, Smeaton I, Harris $R$. Autoimmunity to native type II collagendistinct genetic subset of rheumatoid arthritis. $\mathcal{F} R$ herumatol 1985; 12: 865-70.

32 Goronzy J, Weyand C M, Fathman C G. Shared T cell recognition sites on human histocompatibility leukocyte antigen class II molecules of patients with seropositive antigen class II molecules of patients with seroposit

33 Gran J T, Husby G, Bratlie A, Thorsby E. HLA haplotypes in multiple case families with rheumatoid arthritis. Clin Rheromatol 1984; 3: 173-80.

34 Christiansen F T, Kelly H, Dawkins R L. Rheumatoid arthritis. In: Albert E D, Baur M P, May $W R$, eds Histocompatibility testing 1984. New York: Springer, 1985: 378-83.

35 Whittingham S, Propert D N. Gm and $\mathrm{Km}$ allotypes, immune response and disease susceptibility. Monogr Allergy 1986; 19:52-70.

36 Klouda P T, Bidwell J L, Bodmer J G, Wasik A, Maddison $P$ J. A possible haplotype association in Felty's syndrome. Dis Markers 1986; 4: 27-8.

37 Solinger A M, Bhatnagar R, Stobo J D. Cellular, molecular, and genetic characteristics of $T$ cell reactivity to collagen in man. Proc Natl Acad Sci USA 1981; 78: 3877-81.

38 Solinger A M, Stobo J D. Immune response gene control of collagen reactivity in man: collagen unresponsiveness in HLA-DR4 negative nonresponders is due to the presence of T-dependent suppressive influences. $F$ Immunol 1982; 129: 1916-20.

39 Banerjee S, Luthra H S, Moore S B, O'Fallon W M. Serum IgG anti-native type II collagen antibodies in rheumatoid arthritis: association with HLA DR4 and lack of clinical arthritis: association with HLA DR4 and lack

40 Collier D H, Kerwar S S, Garovoy M R, Fye K H, Stobo J D. Anticollagen antibodies and immune response gene products in rheumatoid arthritis. Arthritis Rhewom 1984; 27 1201-9.

41 Wooley P H, Luthra H S, O'Duffy J D, Bunch T W, Moore $S$ B, Stuart J M. Antitype II collagen antibodies in rheumatoid arthritis: the influence of HLA phenotype. Tissue Antigens 1984; 23: 263-9.

42 Ström H, Al-Balaghii S, Möller E. No demonstrable association between HLA DR4 and in vitro collagen reactivity as determined by the production of leukocyte inhibition factor. Tissue Antigens 1984; 24: 174-83. 